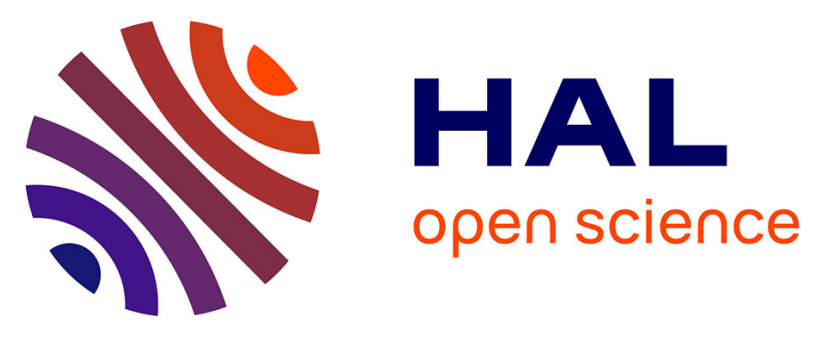

\title{
Feasibility of capecitabine and oxaliplatin combination (XELOX) chemotherapy without central venous access device in patients with stage III colorectal cancer
}

Alexandra Lapeyre-Prost, Marine Hug De Larauze, Benoist Chibaudel, Marie Line Garcia, Veronique Guering-Meyer, Olivier Bouché, Eveline Boucher, Marc Ychou, Jérôme Dauba, Stéphane Obled, et al.

\section{To cite this version:}

Alexandra Lapeyre-Prost, Marine Hug De Larauze, Benoist Chibaudel, Marie Line Garcia, Veronique Guering-Meyer, et al.. Feasibility of capecitabine and oxaliplatin combination (XELOX) chemotherapy without central venous access device in patients with stage III colorectal cancer. Clinical Colorectal Cancer, 2016, 15 (3), pp.250-256. 10.1016/j.clcc.2015.11.004 . hal-01239814

HAL Id: hal-01239814

https://hal-univ-rennes1.archives-ouvertes.fr/hal-01239814

Submitted on 14 Jan 2016

HAL is a multi-disciplinary open access archive for the deposit and dissemination of scientific research documents, whether they are published or not. The documents may come from teaching and research institutions in France or abroad, or from public or private research centers.
L'archive ouverte pluridisciplinaire HAL, est destinée au dépôt et à la diffusion de documents scientifiques de niveau recherche, publiés ou non, émanant des établissements d'enseignement et de recherche français ou étrangers, des laboratoires publics ou privés. 


\section{Original Study}

Short title: XELOX Without CVAD in Colorectal Cancer

Feasibility of Capecitabine and Oxaliplatin Combination Chemotherapy Without Central Venous Access Device in Patients With Stage III Colorectal Cancer

Alexandra Lapeyre-Prost ${ }^{1,2}$

Marine Hug de Larauze

Benoist Chibaudel ${ }^{2,3}$

Marie Line Garcia ${ }^{4}$

Veronique Guering-Meyer

Olivier Bouché

Eveline Boucher $^{7}$

Marc Ychou ${ }^{8}$

Jérôme Dauba ${ }^{9}$

Stéphane Obled ${ }^{10}$

Astrid Lièvre ${ }^{11,12}$

David Malka ${ }^{13,14}$

Roger Faroux ${ }^{15}$

Isabelle Bonnet ${ }^{16}$

Julien Taieb ${ }^{1}$

Thierry André2,4, , 17,*

thierry.andre@aphp.fr

on behalf of the Groupe Coopérateur Multidisciplinaire en Oncologie, the Fédération Francophone de la Cancérologie Digestive, and the UNICANCER Investigators of the PRODIGE Intergroup

1Department of Gastroenterology and Digestive Oncology, Hôpital Européen Georges Pompidou, Paris, France

${ }^{2}$ Multidisciplinary Oncology Research Group (Groupe Coopérateur Multidisciplinaire en Oncologie), Paris, France

${ }^{3}$ Department of Medical Oncology, Institut Hospitalier Franco-Britannique, Levallois-Perret, France

${ }^{4}$ Department of Medical Oncology, Hôpital Saint-Antoine, Paris, France

${ }^{5}$ Department of Medical Oncology, Institut de Cancérologie de l'Ouest Paule Papin, Angers, France

${ }^{6}$ Department of Gastroenterology and Digestive Oncology, Hôpital Robert Debré, Reims, France

${ }^{7}$ Department of Medical Oncology, Centre Eugène Marquis, Rennes, France 
${ }^{8}$ Department of Medical Oncology, Centre Régional de Lutte Contre le Cancer Val d'Aurelle, Montpellier, France

${ }^{9}$ Department of Medical Oncology, Hôpital Layne, Mont-de-Marsan, France

${ }^{10}$ Department of Hepatogastroenterology, Centre Hospitalier Universitaire Carémeau, Nîmes, France

${ }^{11}$ Department of Medical Oncology, Institut Curie, Hôpital René Huguenin, Saint-Cloud, France

${ }^{12}$ Université Versailles Saint-Quentin-en-Yvelines, Versailles, France

${ }^{13}$ Department of Surgical Oncology, Institut Gustave Roussy, Villejuif, France

${ }^{14}$ Department of Medical Oncology, Institut Gustave Roussy, Villejuif, France

${ }^{15}$ Department of Gastroenterology, Centre Hospitalier Départemental de La Roche-sur-Yon Les Oudairies, Roche-sur-Yon, France

${ }^{16}$ Department of Medical Oncology, Hôpital Jean Bernard, Valenciennes, France

${ }^{17}$ Université Pierre et Marie Curie Paris 6, Paris, France

*Address for correspondence: Thierry André, MD, Department of Medical Oncology, Hôpital Saint Antoine, 184 rue du Faubourg Saint Antoine, Paris 75012, France

\section{Micro-Abstract}

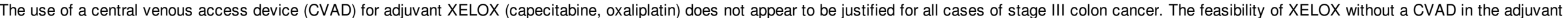
setting for stage III patients was evaluated. Our results confirm the feasibility of this approach in $81.2 \%$ of patients for whom a CVAD was not placed before the first chemotherapy cycle.

\section{Abstract}

\section{Background}

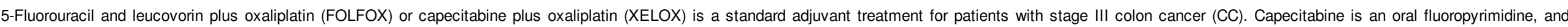

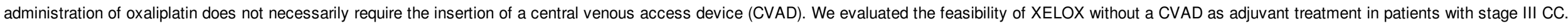

\section{Patients and Methods}

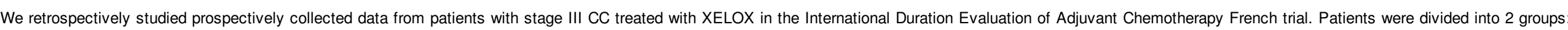

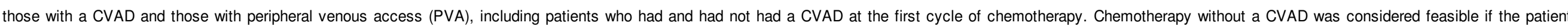
received all cycles of adjuvant therapy without it.

\section{Results}

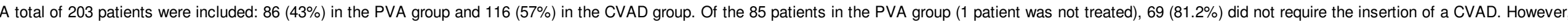

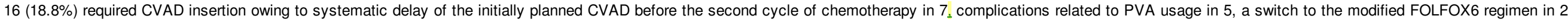

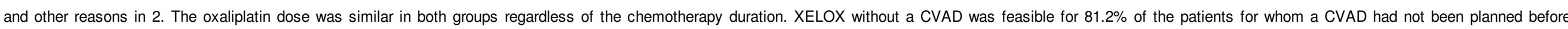
chemotherapy and for $88.4 \%$ of patients for whom chemotherapy was planned without the use of a CVAD.

Conclusion

XELOX chemotherapy without a CVAD is a feasible approach for treating patients with stage III CC in the adjuvant setting 


\section{Introduction}

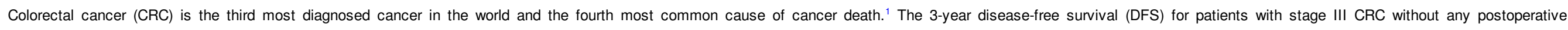
chemotherapy has ranged from $44 \%$ to $52 \% .^{2,3}$ The standard adjuvant treatment for patients with stage III colon cancer consists of the combination of folinic acid, 5-FU, and oxaliplatin (FOLFOX), administered for 6 months. ${ }^{47}$

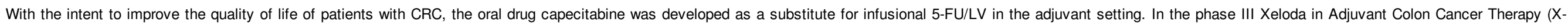

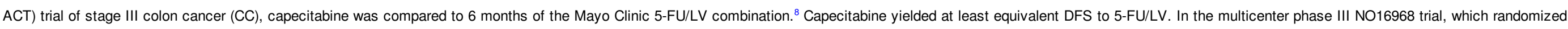

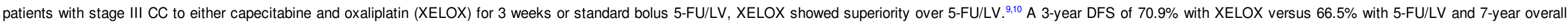

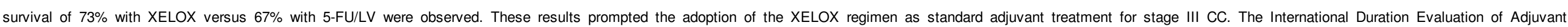

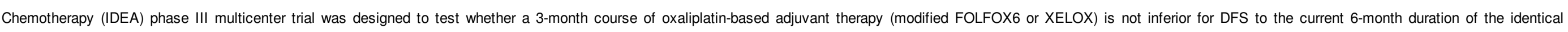
treatment. ${ }^{11}$

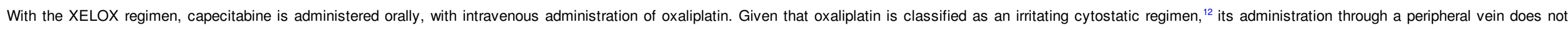

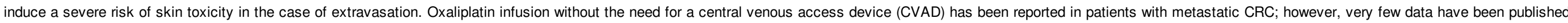

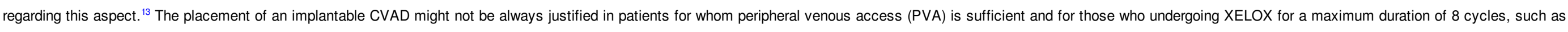

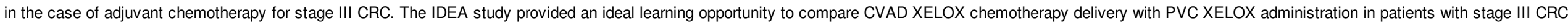

The present study used an extraction of the IDEA FRANCE database to evaluate the feasibility of XELOX chemotherapy without a CVAD as adjuvant treatment of stage III CC.

\section{Patients and Methods}

\section{Patients}

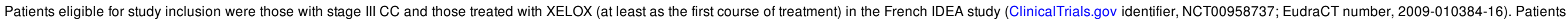
were excluded from the present analysis if the first cycle of chemotherapy had been the FOLFOX6 modified regimen

Each patient provided written informed consent before undergoing any study-related procedures. The study was conducted in accordance with the Declaration of Helsinki and Good Clinical Practice guidelines

\section{Study Design}

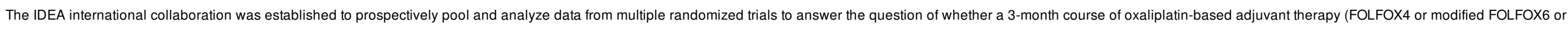

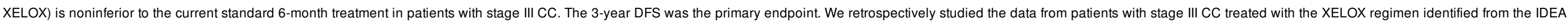

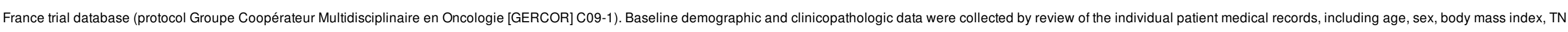

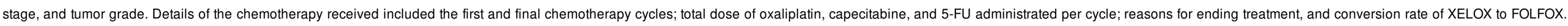

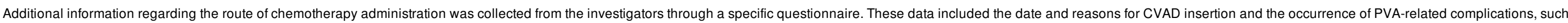

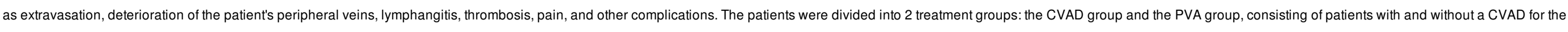
first chemotherapy cycle, respectively.

\section{Treatment}

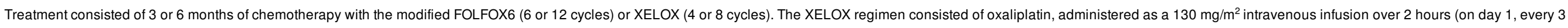

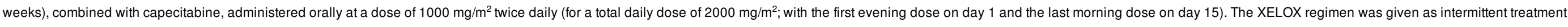

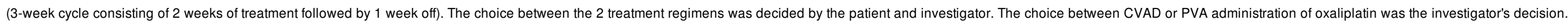




\section{Study Endpoints}

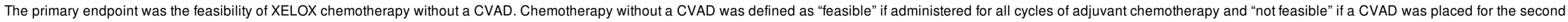

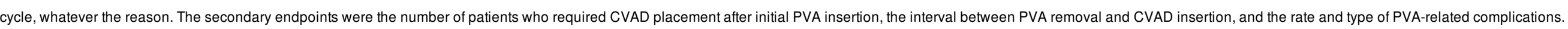

The conversion rate from XELOX to FOLFOX and the exposure to oxaliplatin therapy (number of cycles and doses) in each group were also evaluated.

\section{Statistical Analysis}

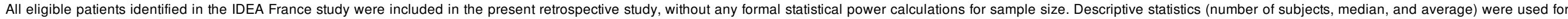

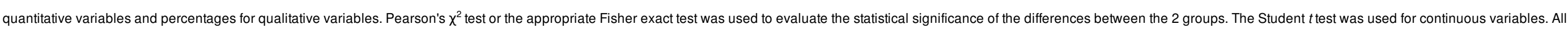
tests were performed 2-sided, and $P<.05$ was considered statistically significant

\section{Results}

\section{Patient Population}

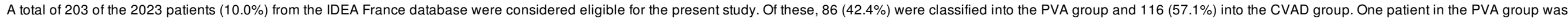
not treated. The main characteristics of the eligible patients are listed in Table 1. The distribution of patient characteristics at baseline was similar between the 2 groups, except for tumor grade differentiation.

\section{Table 1 Baseline Patient Characteristics}

\begin{tabular}{|c|c|c|c|}
\hline Characteristic & CVAD Group $(n=116)$ & PVA Group $(n=86)$ & $P$ Value \\
\hline \multicolumn{4}{|l|}{ Age (years) } \\
\hline Median & 66 & 64 & .50 \\
\hline Range & $35-86$ & $20-87$ & - \\
\hline$>70$ years & $38(32.8)$ & $26(30.2)$ & .69 \\
\hline Sex & & & .63 \\
\hline Male & $69(59.4)$ & $54(62.8)$ & \\
\hline Female & 46 (39.6) & $32(37.2)$ & \\
\hline $\mathrm{BMI}\left(\mathrm{kg} / \mathrm{m}^{2}\right)$ & & & .50 \\
\hline Median & 25 & 24 & \\
\hline Range & $16-42$ & $16-36$ & \\
\hline Chemotherapy delay & & & .73 \\
\hline$>4 \mathrm{wk}$ & $108(93.1)$ & $82(95.3)$ & \\
\hline$\leq 4 \mathrm{wk}$ & $5(4.3)$ & $3(3.5)$ & \\
\hline Unknown & $3(2.6)$ & $1(1.2)$ & \\
\hline Treatment arm & & & .46 \\
\hline $3 \mathrm{mo}$ & $64(55.2)$ & $43(50)$ & \\
\hline
\end{tabular}




\begin{tabular}{|c|c|c|c|}
\hline $6 \mathrm{mo}$ & $52(44.8)$ & $43(50)$ & \\
\hline T stage & & & .052 \\
\hline $\mathrm{T} 1$ & $1(0.9)$ & $7(8.1)$ & \\
\hline T2 & 13 (11.2) & $7(8.1)$ & \\
\hline T3 & 85 (73.3) & $57(66.3)$ & \\
\hline T4 & $17(14.6)$ & $14(16.3)$ & \\
\hline Unknown & $0(0)$ & $1(1.2)$ & \\
\hline$N$ stage & & & .24 \\
\hline $\mathrm{N} 1$ & 91 (78.4) & $73(84.9)$ & \\
\hline N2 & $25(21.6)$ & $13(15.1)$ & \\
\hline Differentiation grade & & & $<.05$ \\
\hline Well & 25 (21.5) & $40(46.6)$ & \\
\hline Moderate & 75 (64.7) & $39(45.3)$ & \\
\hline Poor & $10(8.6)$ & $2(2.3)$ & \\
\hline Unknown & $6(5.2)$ & $5(5.8)$ & \\
\hline
\end{tabular}

Data presented as $n(\%)$, unless otherwise noted.

Abbreviations: $\mathrm{BMI}=$ body mass index $\mathrm{CVAD}=$ central venous access device; $\mathrm{PVA}=$ peripheral venous access

Table 2 Chemotherapy Exposure

\begin{tabular}{|c|c|c|c|c|c|c|}
\hline \multirow[t]{2}{*}{ Oxaliplatin } & \multicolumn{3}{|c|}{ XELOX $3 \mathrm{mo}$} & \multicolumn{3}{|c|}{ XELOX 6 mo } \\
\hline & CVAD Group $(n=64)$ & PVA Group $(n=43)$ & $P$ Value & CVAD Group $(n=52)$ & PVA Group $(n=43)$ & $P$ Value \\
\hline Median no. of cycles & 4 & 4 & NA & 8 & 7 & NA \\
\hline Median dose $\left(\mathrm{mg} / \mathrm{m}^{2}\right)$ & 878 & 882 & .23 & 1430 & 1306 & .55 \\
\hline
\end{tabular}

Abbreviations: $\mathrm{CVAD}=$ central venous access device; NA = not applicable; $\mathrm{PVA}=$ peripheral venous access; $\mathrm{XELOX}=$ capecitabine and oxaliplatin.

\section{Chemotherapy Administration}

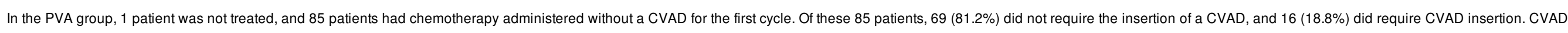

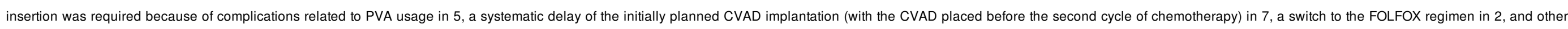

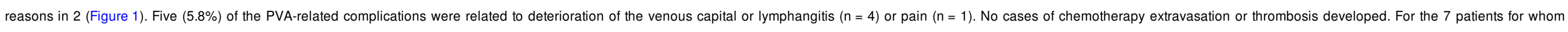

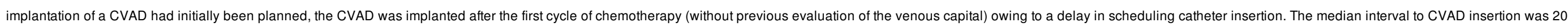
days (range, 5-88). Of the 7 patients in the systematic delayed insertion group (Figure 1), 6 received XELOX for 6 months and 1 received XELOX for 3 months. 


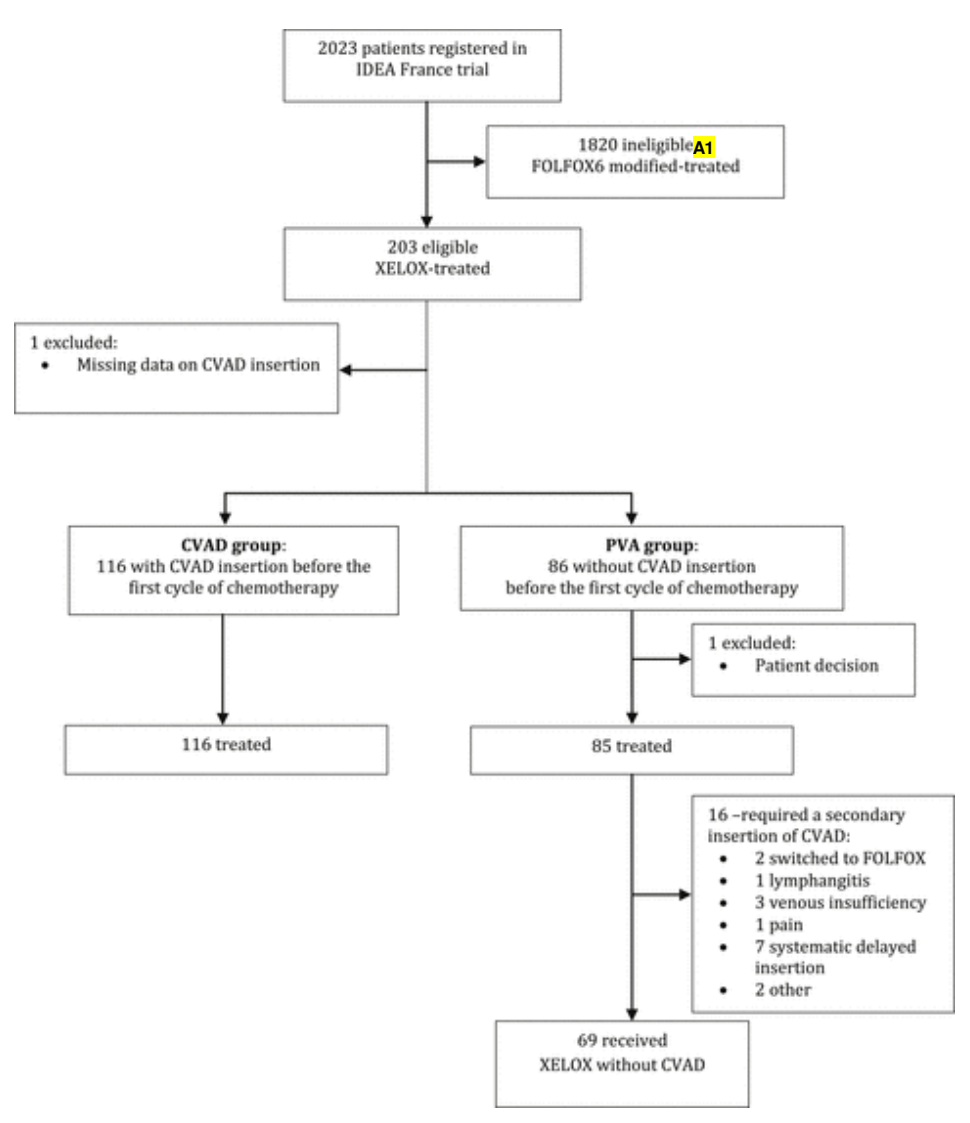

Figure 1 Flow Chart

Abbreviations: $\mathrm{CVAD}=$ central venous access device; modified FOLFOX6 = 5-fluorouracil and leucovorin plus oxaliplatin; IDEA = International Duration Evaluation of Adjuvant Chemotherapy; PVA = peripheral venous access; $X E L O X=$ capecitabine, oxaliplatin. Annotations:

A1. modified FOLFOX6-treated

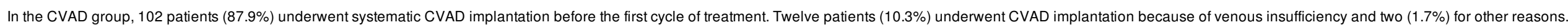

The conversion rate from XELOX to FOLFOX6 modified was $2.3 \%$ in the PVA group and $7.7 \%$ in the CVAD group.

\section{Oxaliplatin Exposure}

In both groups (CVAD and PVA), patients treated with

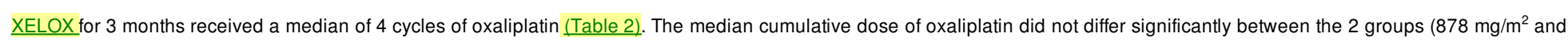

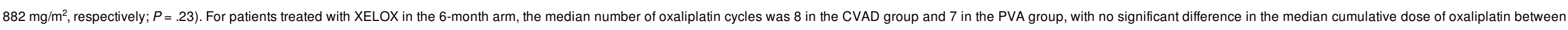
the 2 groups $\left(1430 \mathrm{mg} / \mathrm{m}^{2}\right.$ and $1306 \mathrm{mg} / \mathrm{m}^{2}$, respectively; $\left.P=.55\right)$.

\section{Discussion}

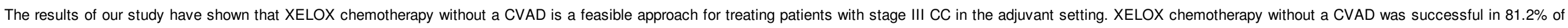
patients for whom a CVAD was not planned before the first cycle of chemotherapy and in

$88.4 \%$ of patients for whom chemotherapy had been planned without the use of CVAD. 


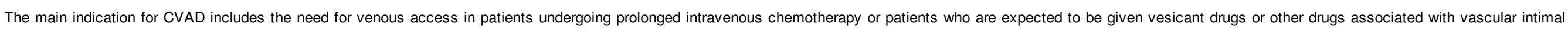

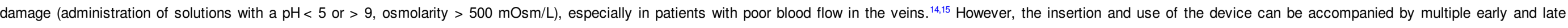

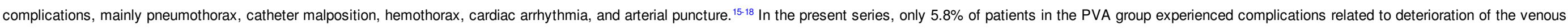

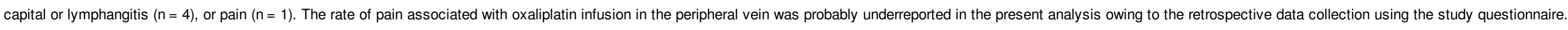

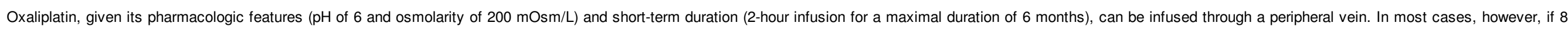
cycles are planned, oxaliplatin infusion will be stopped before the end of treatment owing to oxaliplatin-induced peripheral neuropathy.

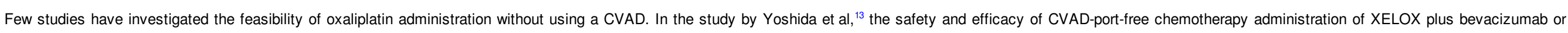

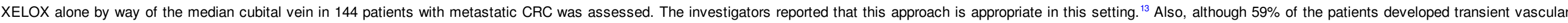

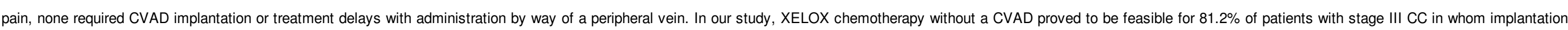

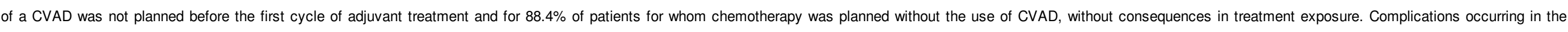

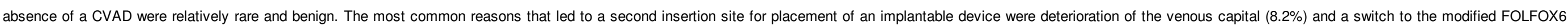

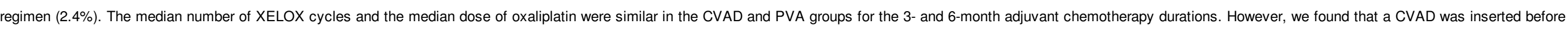

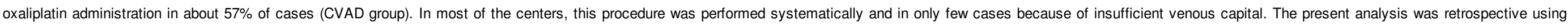
data collected from a questionnaire sent to the principal investigators and therefore clearly subject to recall bias and prone to incomplete data.

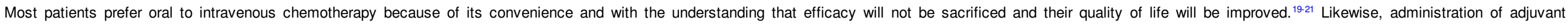

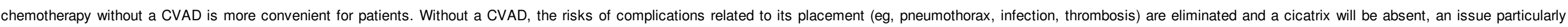

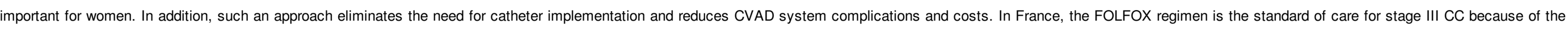

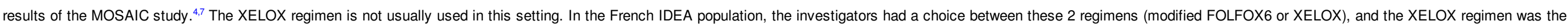

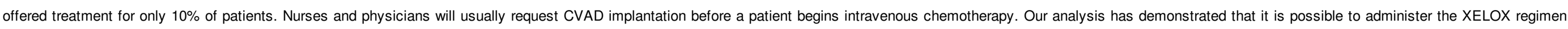
without a CVAD for most patients.

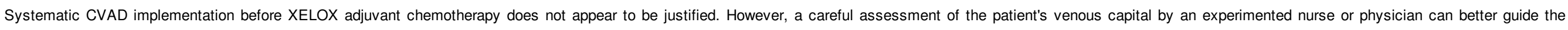

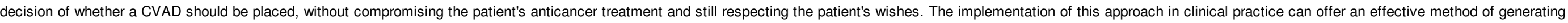

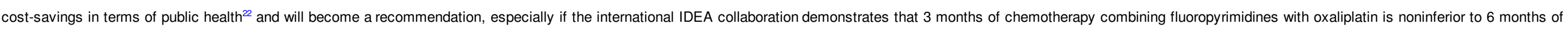
chemotherapy.

\section{Conclusion}

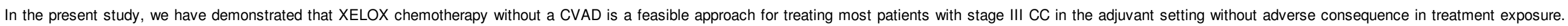

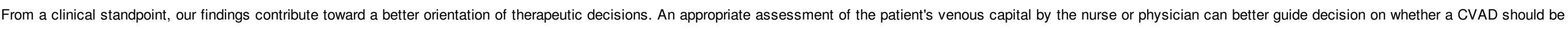
placed, with the aim of maximizing the patient's anticancer treatment benefit and minimizing the impairments to the patient's quality of life.

\section{Clinical Practice Points}

- The standard adjuvant treatment regimens for patients with stage III CC consists of the combination of fluoropyrimidine (intravenous 5-FU and LV or oral capecitabine) and oxaliplatin (FOLFOX or XELOX) for 6 months

- Oxaliplatin administration through a peripheral vein does not induce a severe risk of skin toxicity in the case of extravasation.

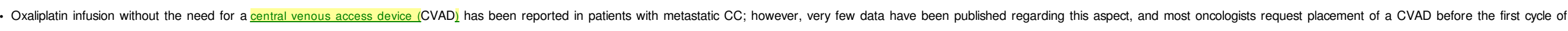
chemotherapy.

- In the present study, $56 \%$ of patients with stage III CC underwent systematic insertion of a CVAD before the first cycle of adjuvant XELOX and $44 \%$ began the first cycle of chemotherapy with PVA and without a CVAD.

- For patients without a CVAD at the first cycle of treatment, $18.8 \%$ required CVAD insertion for the second cycle for different reasons, principally related to deterioration of the venous capital or lymphangitis. 
- A careful assessment of the patient's venous capital by an experienced nurse or physician can better guide the decision of whether a CVDA should be placed, without compromising the patient's anticancer treatment and respecting the patient's wishes.

\section{Disclosure}

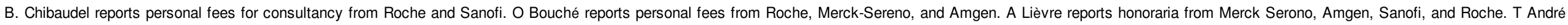
reports personal fees from Roche, Amgen, Sanofi, and Merck. No potential conflicts of interest were disclosed by the other authors.

\section{Acknowledgments}

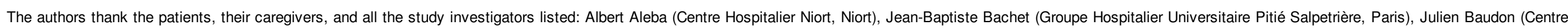

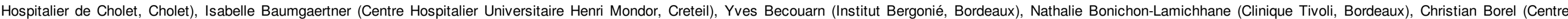

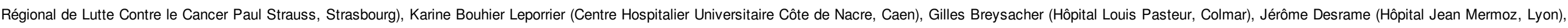

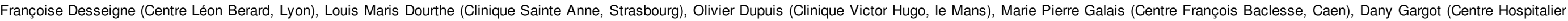

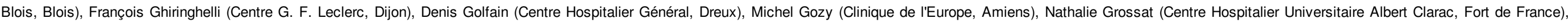

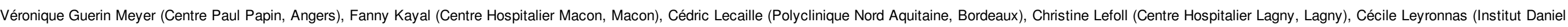

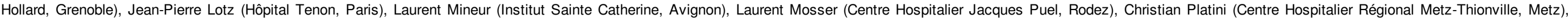

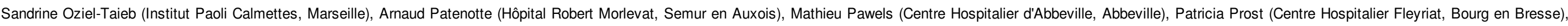

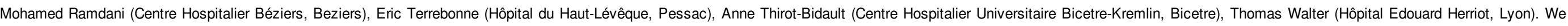

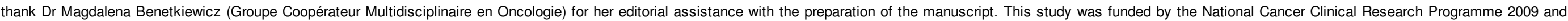
the French National Cancer Institute.

\section{References}

1

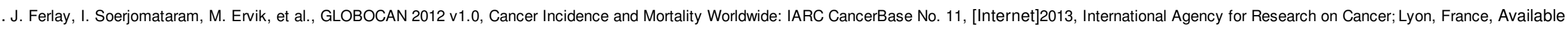
at: http://globocan.iarc.fr, Accessed April 24, 2015.

2

. C.G. Moertel, T.R. Fleming, J.S. Macdonald, et al., Levamisole and fluorouracil as adjuvant therapy of resected colon carcinoma, N Engl J Med 322, 1990, 352-358.

. International Multicentre Pooled Analysis of Colon Cancer Trials (IMPACT) Investigators, Efficacy of adjuvant fluorouracil and folinic acid in colon cancer, Lancet 345, $1995,939-944$.

. T. André, C. Boni, M. Navarro, et al., Improved overall survival with oxaliplatin, fluorouracil, and leucovorin as adjuvant treatment in stage II or III colon cancer in the MOSAIC trial, J Clin Oncol 27, $2009,3109-3116$.

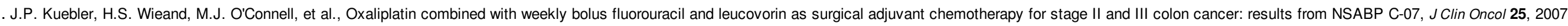
2198-2204.

6

G. Yothers, M.J. O'Connell, C.J. Allegra, et al., Oxaliplatin as adjuvant therapy for colon cancer: updated results of NSABP C-07 trial, including survival and subset analyses, $J$ Clin Oncol 29 , $2011,3768-3774$. 


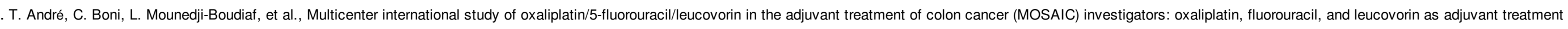
for colon cancer, N Engl J Med 350, 2004, 2343-2351.

8

. C. Twelves, A. Wong, M.P. Nowacki, et al., Capecitabine as adjuvant treatment for stage III colon cancer, N Engl J Med 352, 2005, $2696-2704$.

9

. D.G. Haller, J. Tabernero, J. Maroun, et al., Capecitabine plus oxaliplatin compared with fluorouracil and folinic acid as adjuvant therapy for stage III colon cancer, J Clin Oncol 29, 2011, 1465-1471.

10

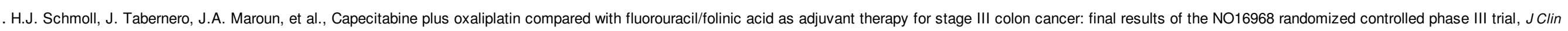
Oncol 33, 2015, 3733-3740.

11

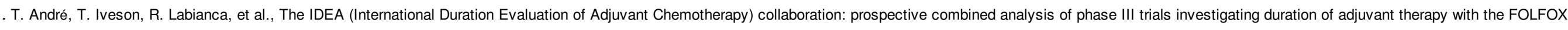
(FOLFOX4 or modified FOLFOX6) or XELOX (3 versus 6 months) regimen for patients with stage III colon cancer: trial design and current status, Curr Colorectal Cancer Rep 9, 2013, 261-269.

12

. Bouchoud L, Rochon F, Decosterd S, et al. Extravasation de cytostatiques: procédure de prise en charge approuvée par la COMED, version 6, 2012. Available at: https://www.yumpu.com/fr/document/view/11734004/extravasation-de-cytostatiques-procedure-de-prise-hug/7. Accessed April 24, 2015.

13

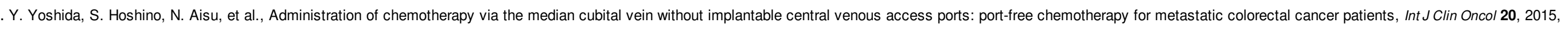
332-337.

14

. G. Maurizio, M. Pittiruti and R. Biffi, Vascular access in oncology patients, CA Cancer J Clin 58, 2008, 323-346.

15

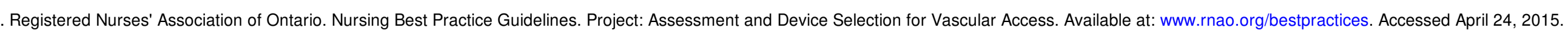

16

. N. Barbetakis, C. Asteriou, A. Kleontas, et al., Totally implantable central venous access ports: analysis of 700 cases, J Surg Oncol 104, 2011, 654-656.

\section{7}

. J.T. Kim, T.Y. Oh, W.H. Chang, et al., Clinical review and analysis of complications of totally implantable venous access devices for chemotherapy, Med Oncol 29, $2012,1361-1364$.

18

H. Sawayama, N. Hayashi, M. Watanabe, et al., The central vein access port and catheter in outpatient chemotherapy for colorectal cancer: a retrospective study of 101 patients, Surg Today 42, $2012,29-34$.

19

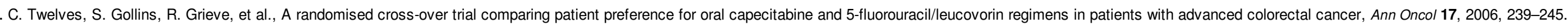

. G. Liu, E. Franssen, M. Fitch, et al., Patient preferences for oral versus intravenous palliative chemotherapy, JClin Oncol 15, 1997, 110-115. 


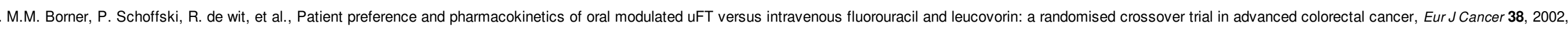
349-358.

22

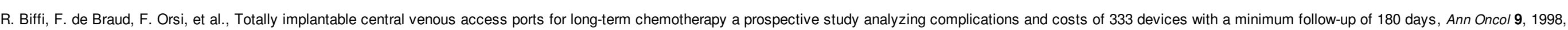
767-773. 